\title{
DISPOSITIVOS Y FLUJOS FINANCIEROS EN EL PAISAJE DE LA EDIFICACIÓN BRASILEÑA
}

\author{
CÉSAR Simoni Santos
}

\author{
Itaquê Santana Barbosa \\ Doctor Geógrafo. Profesor de Geografía de la Universidad de São Paulo \& \\ Doctor Sociólogo. Professor del Instituto Educacional del Estado de São Paulo
}

https://dx.doi.org/10.12795/astragalo.2018.i25.07

El espacio urbano, la vivienda, la calle, el barrio y la ciudad fueron producidos históricamente con vista a su uso como tal. El desarrollo del capitalismo completó y profundizó la transformación del espacio urbano en una mercancía, marcando la entrada definitiva de esa dimensión de la vida en el conjunto de los objetos que pasan a estar al servicio de la acumulación. Actualmente, el proceso de producción y circulación de esa mercancía comporta diversas oportunidades para la reproducción capitalista. Más recientemente, se ha vuelto casi imposible abordar la temática sin hacer ninguna mención a la emergencia de formas financieras de acumulación que pasan, éstas también, a apoyarse crecientemente en los segmentos, en las estrategias y en las dinámicas espaciales urbanas.

A lo largo de las últimas décadas, se ha desarrollado en Brasil un campo de estudios sobre el proceso de financierización del segmento inmobiliario. A partir de enfoques alineados con la economía política, diversos autores propusieron lecturas con miradas diferentes respecto de los caminos por donde esa financierización se estaría dando. Este artículo, partiendo de reflexiones acerca de los medios por los cuales el proceso de acumulación se mantiene en curso en la producción y circulación capitalista del espacio urbano, trata de presentar una parte significativa del universo de flujos y dispositivos financieros que se mantuvieron implicados en el sector de la edificación, como parte de una trama que constituye uno de los medios por los que el espacio y la vida urbana se ven usurpados.

En cierta forma, el desarrollo de ese nicho de mercado, que inserta la producción del espacio urbano en la base de la acumulación financiera mundializada, se presenta como 
una de las más recientes formas de los antiguos mecanismos de subordinación de la actividad social y de las dinámicas territoriales latinoamericanas, llevándose consigo el potencial de actualización del debate sobre la dependencia. La dominación financiera, que se ejerce sobre los recientes procesos de urbanización en América Latina, ha ayudado a completar el cuadro que colocó a Brasil en la condición de una 'plataforma de la valorización financiera internacional' (PAULANI, 2008). En ese enmarañado, que compone el universo de una nueva etapa de integración subalterna del continente, como parece ya poder ser señalado como una característica de diversas formaciones nacionales, el Estado y el fondo público no están ausentes.

En esta nueva etapa, el Estado ya no es el del desarrollismo. La crisis de la deuda de los años 1980 engendró nuevas condiciones. Las políticas de industrialización fueron sustituidas por las de austeridad. La esperanza de la modernidad fue suplantada por el letargo neoliberal. Las políticas sociales construidas en la posguerra, para integrar a los trabajadores al capitalismo, ahora se convierten en nuevos frentes de acumulación para el capital internacional.

Sobre todo, a partir de mediados del siglo XX, en un ambiente de guerra fría, se vio la expansión de las funciones del Estado, con el desarrollo de políticas de regulación económica y de promoción de condiciones de bienestar para los trabajadores por medio de salarios indirectos. Esto permitió también la recalificación y ampliación de las políticas sociales, aunque de forma muy restringida, en la periferia del capitalismo. En Brasil, en lo que se refiere a la política habitacional, por ejemplo, a lo largo de ese período, vimos al Estado salir de la producción directa hacia una 'asociación' cada vez más profunda con la iniciativa privada. Inicialmente, encargando edificios con proyectos y ubicaciones enteramente definidas por él. Más tarde, ya en los años 90, encomendando determinadas cantidades de unidades habitacionales en ciertas ciudades, con tipologías y ubicaciones sugeridas, ya, por la iniciativa privada. Los cambios como éstos, a lo largo del período, permitieron cada vez más la ampliación de las ganancias privadas en ese sector, permitiendo a ese capital obtener ganancias más allá de los derivados de la extracción directa de plusvalía en el proceso productivo bajo su mando (BARBOSA, 2010).

Sin embargo, a partir de la segunda mitad de los años 90, el Estado pasa a desarrollar “alianzas”" con nuevas fracciones del capital, articuladas directamente con el mercado financiero internacional. Para algunos, el desarrollo de esa relación podría llevar a la constitución de una nueva forma de financiamiento de la política de vivienda, basada en un mercado secundario de deudas, que supuestamente superaría el antiguo sistema, qoe en Brasil es representado por el Sistema Financiero de la Vivienda (SFH por sus siglas en portugués). El SFH fue formulado en la segunda mitad del siglo XX, basado en la movilización de recursos de ahorro regulados y garantizados por el gobierno. El Sistema Brasileño de Ahorro y Préstamo (SPBE) que financia la producción habitacional destinada a la clase media y alta, y el Fondo de Garantía por Tiempo de Servicio (FGTS) que debería financiar las otras capas de la población, donde se concentra el déficit, constituyeron la base del $\mathrm{SFH}$. Ellos son remunerados con tasas de interés inferiores a las de mercado, introduciendo una especie de subsidio en las financiaciones 
del sistema. El principal brazo operativo de ese sistema fue el Banco Nacional de la Vivienda (BNH), responsable de la producción de viviendas sociales.

Los dispositivos forjados con la perspectiva de superación del SFH y de acercamiento del mercado financiero han sido ampliamente responsables de la conversión del espacio urbano en uno de los fundamentos de la acumulación mundializada de capital, actualizando la política social de vivienda al nuevo tiempo del mundo. De esta forma es posible pensar que, por medio de tales dispositivos e instrumentos, tanto los flujos de capital-dinero desterritorializado aportan en determinadas plazas en busca de los fundamentos de la mercancía inmobiliaria, como la propia mercancía inmobiliaria territorialmente fijada, gana una dimensión mobiliaria por medio de los títulos y papeles que cargan sus promesas para los muchos mercados de capitales mundo afuera.

El debate sobre las formas de contacto y relación entre el mercado inmobiliario y el mercado de capitales ha revelado, dentro de ese gran universo ligado a las finanzas ${ }^{1}$, una miríada de agentes, posiciones, instrumentos y productos. El desarrollo de cada uno de los dispositivos asociados a esta relación, entre el mercado de capitales y el mercado inmobiliario, no ocurrió, sin embargo, de forma homogénea en el tiempo y en el espacio. Con la intención de contribuir a una síntesis de las posibilidades analíticas, se buscó en este artículo algunos

1 Chesnais emplea el término 'finanza' 'para designar simultáneamente a las instituciones especializadas en la centralización del dinero 'inactivo' en busca de colocación en préstamos o en títulos' y la capacidad de 'imponer a las empresas las normas a ser respetadas en materia de rentabilidad y, entonces, el grado de explotación de la fuerza de trabajo vivo que ellas deben alcanzar '(CHESNAIS, 2010: 100). caminos para la presentación de un diagrama capaz de organizar el entendimiento sobre el papel y los efectos de algunos dispositivos financieros respaldados en operaciones inmobiliarias. Para dar cuenta de esta tarea, el artículo está dividido en dos grandes partes, además de esta introducción y de algunas consideraciones finales.

En la primera parte, algunas de las principales posiciones engendradas en este proceso se localizan a partir de un esquema general de la circulación del capital, que considera las formas de interacción entre las finanzas y los negocios inmobiliarios. Este esquema está amparado en la elaboración de un diagrama representativo de los flujos de valores, bienes inmuebles y títulos. La ventaja de la representación esquemática reside en iluminar la posición de cada dispositivo movilizado en esa interacción.

Para abordar los elementos de funcionamiento de algunos dispositivos, en la segunda parte del artículo se recurrió al debate sobre la llamada financierización del mercado inmobiliario brasileño. En el marco de este debate, la mayoría de los instrumentos y dispositivos se abordaron desde una perspectiva crítica. Uno de los elementos destacados de la segunda parte es la presencia de un cuadro sinóptico, que presenta algunos de los principales dispositivos que actualmente caracterizan el funcionamiento de la esfera financiera vinculada a los negocios inmobiliarios en el mercado brasileño. Además de presentar, el cuadro caracteriza y propone una sistematización de los dispositivos a partir de los períodos en que fueron abordados. 


\section{1 - FLUJOS DE VALOR EN EL SECTOR DE LA EDIFICACIÓN}

A partir de uno de los esquemas más difundidos acerca de la fórmula general del capital, tenemos la siguiente representación: $D-M-D$ '. David Harvey (2006: 21), apoyándose en un pasaje poco relevante, pero original y tomada del mismo capítulo en que Marx presenta la formulación general del capital, desdobla $D^{\prime}$ en $D+\Delta D$, teniendo la siguiente fórmula: $D-M-(D$ $+\Delta D$ ). Christian Topalov (1979: 59), observando más pormenorizadamente la industria de la construcción, enfatiza el proceso de trabajo implicado en las actividades de transformación que son responsables de la valorización del capital productivo, destacando el momento de la producción (P) en su diagrama:

$$
\mathrm{D}-\mathrm{M} / \mathrm{P} / \mathrm{M}^{\prime}-\mathrm{D}^{\prime}
$$

Este diagrama, sin embargo, todavía no avanza en la dirección de lo que ocurre y de la propia división del capital en el momento de la producción. Desentrañando aún más los términos de esa representación esquemática, Harvey (2006, pp. 69 y 132), llega a la siguiente formulación: D - M (FT/MP) ...P ...M' - D'. En esta última configuración aparecen más explícitamente representados los medios de producción (MP) y la fuerza de trabajo (FT) como componentes del universo de las mercancías adquiridas como condición para el proceso de producción (P), el cual presenta como resultado una nueva mercancía (producida) con un valor agregado por el proceso de trabajo (M') que, una vez vendida, convertida, por lo tanto, en dinero, asume la forma D'.

Como, para la observación del caso específico de la industria de la construcción en el ramo de la edificación, se considera importante la separación de los componentes del llamado capital constante, como veremos más adelante, se adopta aquí una tercera forma de representación derivada de la fórmula general del capital. Es así porque, entendiendo el coste del terreno y el valor suelo simultáneamente como parte del capital constante circulante de esa industria (LEFÈVRE, 1982) y posible fuente de lucros extraordinarios para cada emprendimiento del ramo (JARAMILLO, 2010; LOJKINE, 1971; SINGER, 1982; SLATER, 2015; SMITH, 1996), es necesario identificar los componentes implicados en la rentabilidad del segmento también en esa parte del capital. El diagrama propuesto (Diagrama 1) trae, en vez de MP, la segmentación del capital constante (cc) en capital fijo (cf), por un lado, y en renta capitalizada (rc) y materias primas (mp), por otro lado, como componentes del capital circulante corriente (ccc); además de ubicar el capital variable (cv).

Considerando la actividad del sector de la edificación, se comprende que una de las formas de valorización del capital puede ser observada en la producción del espacio urbano, y eso ocurre como función del capital productivo. Es decir, como valor que se acumula y se amplifica por la explotación de la fuerza de trabajo en el proceso productivo que produce y reproduce materialmente el espacio urbano.

En el diagrama (Diagrama 1), los momentos de la formulación general original del capital reaparecen en sus posiciones. Además, explicita el carácter cíclico, aunque no expresando la dimensión acumulativa posibilitada por la repetición de ese ciclo, y resalta tres instancias: la movilización del valor (D) a ser convertido en las mercancías necesarias para el proceso productivo (M); la 


\section{Diagrama 1 - Detalle de la fórmula general del capital para el sector de la edificación}

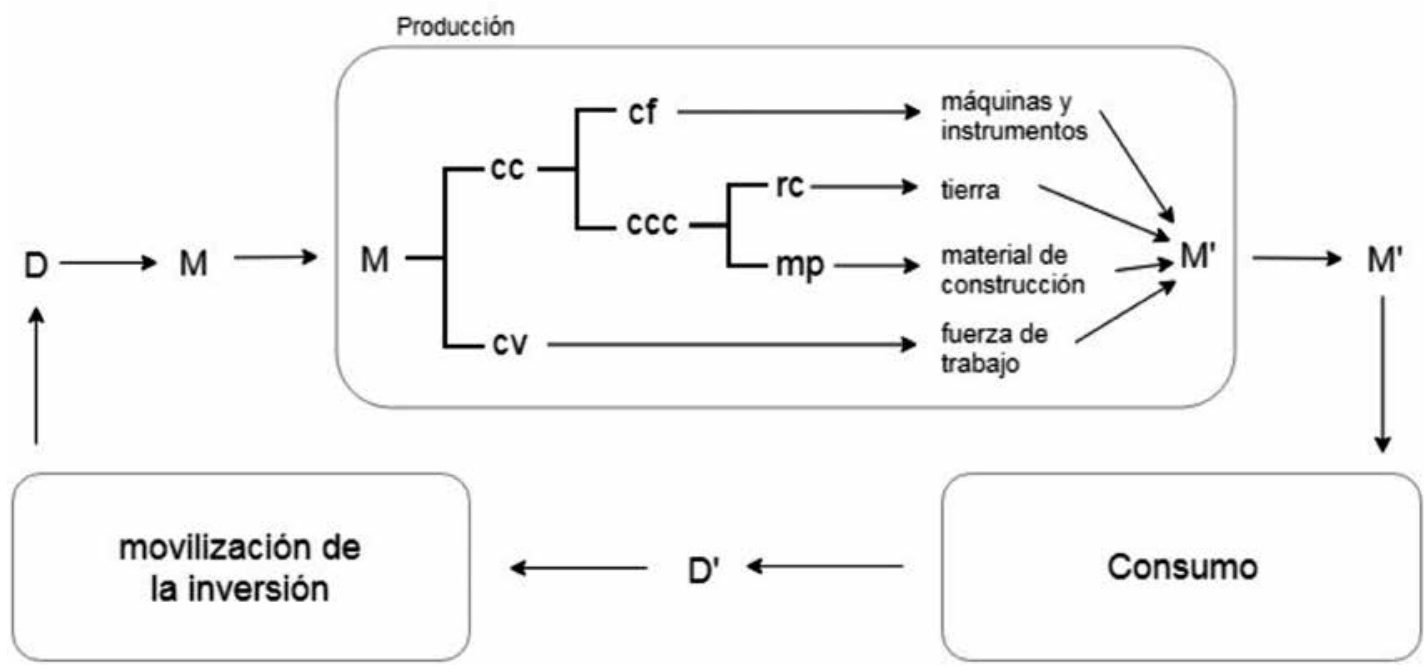

Diagrama elaborado por los autores

conversión de la mercancía resultante (M') a la forma de dinero (D'); y la producción de la mercancía (M') a partir de las mercancías necesarias (M), instancia detallada considerando las particularidades del ramo de la edificación. En este ramo, la tierra no es sólo el soporte sobre el cual la producción se realiza, sino que compone y acompaña la mercancía resultante del proceso productivo, siendo parte del capital constante circulante (ccc). Sin embargo, la tierra, por sus propiedades naturales y sociales, da derecho a una renta, lo que se expresa como renta capitalizada (rc) en su precio para el proceso productivo.

En este sector, como en otros, dados el precio de mercado para una determinada mercancía, una jornada de trabajo estándar y un nivel de salario, condiciones éstas nunca plenamente establecidas en la periferia del capitalismo, la variación de la ganancia entre capitales del mismo volumen se dará en la función inversa al tamaño relativo de ese nivel salarial en el precio de mercado de la unidad de la mercancía resultante del proceso productivo específico de cada capital en particular, por lo tanto, de la tasa de explotación de la fuerza de trabajo. Es decir, en función de la variación de la composición orgánica de esos capitales en la producción, derivada específicamente del aumento del capital fijo, pues el valor de la unidad de la mercancía producida por él es dado por el nivel de desarrollo de su proceso productivo, pero el precio de mercado de ella se determina por el nivel de desarrollo de la producción de dicho seguimiento en general.

Otra forma de obtención de ventajas competitivas puede estar asociada al descenso de los costos de la parte relativa al capital constante (cc). En estos términos, si consideramos el costo de adquisición del terreno ( $\mathrm{rc}$ ) como parte del capital constante circulante (ccc) de esa industria, como lo hizo Rodrigo Lefèvre 
(1982), los terrenos normalmente sin atributos diferenciales serían portadores de ventajas para la contabilidad del emprendimiento, ya que podrían contribuir, en función de sus bajos costos, a una reducción de los precios de producción y de la composición orgánica del capital (aunque éste mantenga una tendencia de elevación en su composición técnica). Este argumento sugiere una inversión del papel de la renta diferencial en la contabilidad del sector de la edificación.

Para que esta estrategia funcione, sin embargo, es necesario contar con formas de financiación al acceso o la facilitación del consumo de los inmuebles que no sean enteramente deducibles de las leyes de mercado. De ahí la gran ventana de oportunidades presentada cada vez que se elabora un gran programa habitacional. Esto ocurre porque las capas de más altos rendimientos y que componen la banda donde se concentra la llamada demanda solvente no compraría los inmuebles ubicados en las áreas en que la participación del costo del terreno (rc) en la composición de capital y en los precios de producción es más bajo. Por lo tanto, la participación de formas politizadas de realización del excedente producido, implementadas por políticas públicas, es una condición para la producción y venta de inmuebles en las áreas periféricas, justamente en las condiciones capaces de proporcionar ventajas en términos de costos y rentabilidad para el capital productivo del ramo de la edificación.

Cuando, por ejemplo, el gobierno, además de subsidiar el consumo de la vivienda, permite que los agentes privados contratados para producir vivienda social escojan la localización de los emprendimientos él está permitiendo que estos tipos de ganancias se incorporen a los beneficios de la operación. En 1993, el Gobierno del Estado de São Paulo lanzó el programa "Llamamiento Empresarial", que se distinguía de la tradición de los programas habitacionales justamente por hacer el pedido de unidades habitacionales por regiones o municipios, no especificando, sin embargo, en qué terrenos, tal como había sido la práctica hasta entonces (BARBOSA, 2008). Dada la libertad para el montaje del proyecto conferida a las promotoras, el resultado fue la adopción del criterio de los terrenos de menor costo.

Sin embargo, la forma de participación del elemento suelo en la búsqueda de beneficios extraordinarios puede variar sensiblemente ${ }^{2}$, incluso contrariando la tesis del "papel invertido" de la renta diferencial en el marco de la contabilidad del ramo de edificaciones, como en ese fragmento extraído de otro trabajo:

The verticalized building, (...) considering its ability to reproduce the benefits of location, defies the unrestrained adoption of Lefèvre's reasoning, according to which,

2 Mucha de esta variación, también, según diversos estudios (JARAMILLO, 2010; LOJKINE, 1971; SINGER, 1982; TOPALOV, 1979) no siempre convergentes o consensuados, se deriva del hecho de que el instituto de la renta de la tierra urbana es multifacético. La inspiración de la mayor parte de estos estudios en las consideraciones de Marx acerca del papel de la propiedad agraria en la regulación del proceso de producción agrícola y en la distribución de la plusvalía en la sociedad como un todo orientó la atención hacia al menos cuatro tipos de renta: absoluta, la renta de monopolio, la renta diferencial I y la renta diferencial II. Como no es el objetivo de este artículo y la discusión acerca de la existencia, de las formas de actuación y de la clasificación de las rentas del suelo urbano son bastante controvertidas, serán rescatados aquí sólo algunos aspectos de ese debate que se mantuvieron más en boga en los últimos tiempos y en la literatura considerada. 
for the construction industry, the ground rent factor would essentially play a reversed role, being accounted for solely as part of the constant circulating capital of the segment (SIMONI-SANTOS, 2018, p. 252). ${ }^{3}$

Otro mecanismo implicado en la obtención de beneficios extraordinarios está relacionado con el cambio en las condiciones de compra y venta del terreno. Dos importantes matrices del pensamiento crítico sobre las dinámicas espaciales urbanas estuvieron implicadas en la resignificación de lo que tradicionalmente entró en el saco de rótulo genérico de la "especulación inmobiliaria". Tanto la "máquina de crecimiento" de Logan y Molotch (1987) y el "rent gap" de Neil Smith (1996) prestaron especial atención a los mecanismos de promoción y captura de las variaciones de precio de terrenos ubicados en áreas específicas de la ciudad con potencial de revalorización. El mecanismo principal, en ambos casos, se refiere a una forma de obtención de ganancias resultantes del diferencial de renta que se expresa en la subida de precio de un conjunto localizado de terrenos e inmuebles.

Algunos factores pueden estar relacionados con esta subida de precios y los emprendedores pueden tener aquí una posición pasiva o activa. El incremento o la realización de mejoras en las infraestructuras (de circulación, ocio, comunicación, etc.) en una determinada

3 "La edificación verticalizada, (...) considerando su capacidad de reproducción de los beneficios de la localización, contraria a la adopción irrestricta del argumento de Rodrigo Lefévre (1982), según el cual, para la industria de la construcción, el factor renta tendría esencialmente un papel invertida, que se contabiliza únicamente como parte del capital constante circulante del segmento". región, la aproximación o la creación de centros de servicios y facilidades de todo el género y la promoción de una imagen positiva asociada a la vecindad son ejemplos de factores que pueden actuar en favor de la creación de ese diferencial de renta, abriendo aquí otro frente de profunda imbricación de la rentabilidad del segmento en relación a la participación del Estado.

Estos son ejemplos de cómo la propiedad de la tierra interfiere en la captura de plusvalías por el segmento inmobiliario y de cómo éste puede actuar en favor de determinadas decisiones. Pero otro frente de interacciones también marca la particularidad del segmento. La relación que la industria de la construcción establece con un "capital de giro autónomo", en los términos de Christian Topalov (1979), no es de la misma naturaleza que la mayor parte de los demás segmentos y necesita ser explicada en los marcos de sus especificidades. Un corolario que se puede extraer del argumento del autor es que tanto por los largos plazos de rotación del capital y por el peso del factor suelo, entendidos como obstáculos naturales a la reproducción del capital en la industria de la construcción, el desarrollo del ramo crea lazos más fuertes y una dependencia más explícita en relación a un capital de giro autónomo (TOPALOV, 1979, pp. 54-57).

El tiempo de rotación del capital invertido en ese segmento, según el argumento (JARAMILLO, 2010, TOPALOV, 1979), es elevado por dos características básicas de la actividad: las peculiaridades del proceso de la producción inmobiliaria y los altos costos de la mercancía final. El proceso de producción en el sector de edificaciones comparado al de otros segmentos es más lento. Luego, se establecen dos campos principales para la observación 
de las formas de participación de ese capital de giro autónomo. El primero está vinculado a la promoción de la oferta, que, además de afrontar los largos períodos de transformación y de trabajo, tiene que encarar las dificultades propias de la primera transfiguración del capital de $\mathrm{D}$ en $\mathrm{M}$, en el pasaje $\mathrm{D}$ - M. Esto ocurre porque, además las dificultades de contratación de fuerza de trabajo (muchas veces reiniciada al menos en parte para cada emprendimiento), la propia adquisición de la tierra no está garantizada y no presenta costos uniformes, ya que la oferta de ese factor es independiente de una producción industrial constante y las características de su mercado son muy particulares, dificultando la planificación de tiempo y de costos para el segmento. El segundo está vinculado a la conversión de M' en D', en el paso M' - D', y, por lo tanto, a la promoción de la demanda que enfrenta, a falta de un capital de giro capaz de solventar esa carencia, los elevados costos de la mercancía producida y los largos períodos de consumo y circulación de la mercancía final.

A partir de las exigencias de reproducción del capital invertido en el sector de la edificación, históricamente, los obstáculos a la industrialización y ampliación de la acumulación de capital en el segmento llevaron a la introducción de mecanismos sostenidos por la participación del fondo público, normalmente a partir de la elaboración de programas habitacionales que tuvieron fuertemente vinculados a la promoción de la circulación del capital en el sector (TOPALOV, 1987). En el marco de la rígida regulación de la oferta de crédito, como cedente directo del capital de giro, el Estado mantuvo una proximidad importante del segmento, lo que incluso llegó a inspirar a Christian Topalov a caracterizar la vivienda como una 'mercancía imposible'. La movilización del ahorro público para financiar la industrialización de la producción inmobiliaria da lugar a una situación en la que el capital productivo se inmuniza del riesgo del salto mortal de la mercancía, una vez que la venta de la mercancía producida es cierta y rápida, quedando los riesgos del financiamiento al comprador final con el fondo público.

Sin embargo, la presencia de ese llamado capital de giro autónomo no fue garantizado exclusivamente por la participación del Estado y, en ese caso, hay que considerar los intereses de un capital privado en la aproximación del segmento. Por el lado de los intereses del capital portador de intereses o de las finanzas, los caminos de aproximación y entrada pueden darse a partir de por lo menos tres frentes distintos, a saber: el crédito al productor; la participación accionaria; y el crédito al consumidor.

La primera de ellas, la más antigua y experimentada modalidad de utilización del capital portador de intereses, puede ser capturada en lo que a menudo se llamó crédito al productor, del cual normalmente participan el fondo público y el capital bancario. En la historia de la industria de la construcción, principalmente en el sector de la construcción pesada, la participación de esa fuente fue una de las grandes responsables de la oligopolización del sector. Más recientemente, la participación de los préstamos, a través de instituciones públicas y bancos privados, pasó a aumentar directamente en el sector de las edificaciones, no sólo como una respuesta esperada en función del calentamiento del mercado, sino también como una forma importante de reparto de los riesgos.

La forma politizada del crédito al 
productor busca amortiguar la oposición fundamental existente entre esas dos formas de capital, a saber: el capital monetario, portador de intereses, por lo tanto, y el capital productivo. En el mercado, en su forma original, el crédito surge como forma de apropiación de parte del excedente social. El dinero concentrado 'se vende como capital', 'el capital como tal ingresa aquí, por consiguiente, en la circulación' (MARX, 2011, págs. 726-727).

Esta no fue la única forma en que el capital monetario concentrado se utilizó para extraer más valor del capital empleado, pero, en el caso de las aplicaciones en forma de acciones, es posible notar algunas diferencias. Una de ellas se refiere al hecho de que 'la tasa de interés para el capital monetario que se pone a disposición en forma de acciones no es, como tal, determinada previamente; en el caso sólo existe el derecho de participación en el rendimiento (lucro) de determinada empresa' (HILFERDING, 1985, pp. 111-112). Esto, sin embargo, abre la posibilidad de que ese capital monetario obtenga beneficios superiores a la tasa media de interés, resultante de la captura de ganancias extraordinarias obtenidas por la empresa, aspecto que se vuelve aún más importante ante la formación de los grandes oligopolios.

Una vez transfigurado en propiedad de parte del capital funcional, ese capital que ingresa permanece vinculado al proceso productivo o a la actividad principal del capital no monetario, abandonando la forma más líquida en la que ingresó en el proceso. "Para que el accionista se convierta en un capitalista monetario, es imperativo que pueda recuperar en cualquier momento su capital en forma de capital monetario" (HILFERDING, 1985: 112). Es precisamente en ese momento que entra en escena el papel desempeñado por las bolsas de valores, completando el movimiento de transformación de la propiedad sobre el capital funcional y sus partes, propia de los tenedores de las acciones, en un "simple título de renta" (CHESNAIS, 2010, 142). Este movimiento completa el proceso de exteriorización del capital invertido en acciones en relación a la actividad base de la empresa capitalista. "Uno de los efectos y características de las sociedades por acciones es llevar al extremo esta 'transformación del capitalista realmente activo en un simple dirigente y administrador de capital de otros, y de los propietarios de capital en simples propietarios, en simples capitalistas financieros'" (CHESNAIS, 2010, p. 117).

Una tercera forma del capital monetario concentrado que drena valor de la economía real está vinculada a la realización de la mercancía y, por lo tanto, a la restitución con beneficio del capital-dinero al productor. El crédito al consumidor, observado desde ese punto de vista, puede ser entendido como una importante 'estrategia empleada por los capitalistas para absorber las tensiones de la sobreacumulación' (SOEDERBERG, 2014, p.27), dando mayor fluidez, haciendo solvente, expandiendo la demanda efectiva. Una de las ramas en las que esta participación se ha vuelto central, por las razones ya presentadas, está vinculada a la oferta de viviendas.

La cuestión de si los rendimientos del crédito al consumidor derivan de una desviación de la plusvalía producida bajo el mando de los capitales realmente activos, hipótesis plausible en condiciones clásicas de acumulación, actualmente, momento en que esa modalidad asume proporciones importantes para el pensamiento social crítico, 
requeriría antes un debate de naturaleza empírica que en el campo categorial. No siendo éste el propósito de la exposición pretendida, basta con tener la determinación última que opera sobre los rendimientos del capital portador de intereses, que nos informa que, así como en el caso de préstamos a los Estados y del mecanismo de la deuda pública, "la forma del capital portador de intereses hace que cada ingreso monetario determinado y regular aparezca como interés de un capital, ya sea de un capital o no" (MARX, 1988, p.44), valiendo esta determinación también para la modalidad del crédito al consumidor.

Así, se puede aceptar la idea de que el dinero a crédito funciona como un elemento de regulación de la producción por dos vías: primero como catalizador de la realización de la plusvalía producida; $y$, en segundo lugar, como forma de empleo lucrativo del capital excedente que no encontraba medios de valorización en otros segmentos. Pero para funcionar efectivamente como capital, ese excedente útil debe operar en condiciones de rentabilidad media, equiparable a sus congéneres aplicados de otras formas. La tendencia a la ecualización de las tasas de interés, inicialmente señalada por Hilferding (1984, p 113) como una función entre el préstamo a intereses fijos y la inversión en acciones, es consecuencia de dos factores cruciales. En primer lugar, del principio de que 'en la sociedad capitalista, toda suma de dinero adquiere la capacidad de rendir interés' (HILFERDING, 1985: 113). En segundo lugar, del hecho de que, para funcionar, ese principio presupone el desarrollo del mercado de capitales a tal punto que las deudas, acciones y títulos más diversos puedan ser reconvertidos a su forma monetaria original en transacciones tan fluidas como sea posible.

De este modo, toda la diversidad que el universo de productos financieros ha asumido en los últimos tiempos es profundamente dependiente del desarrollo de mercados secundarios en los que puedan circular esos papeles. Así como la bolsa de valores lo fue y ha sido para la ampliación de las operaciones de compra y venta de acciones, la securitización ha servido para ampliar la producción y el mercado de deudas resultante de la expansión de las diversas modalidades de crédito al consumidor. Este fue también el mecanismo que proporcionó una avalancha de títulos en el mercado que 'se presentan a los ojos de quien los detiene (...) como un capital, un derecho permanente de recibir flujos de ingresos regulares que provienen del reparto de los resultados de la riqueza en la que no importa saber quién la produjo y cómo fue producida' (CHESNAIS, 2010, pp. 97-98).

Por lo tanto, el Diagrama 2 busca representar los flujos de valores, bienes y títulos entre las diferentes posiciones involucradas en los procesos alternativos de financiamiento de la oferta y de la demanda por edificaciones. Como hemos visto en el diagrama 1 , el resultado del proceso productivo es una mercancía (M') con más valor que la suma de los valores de las mercancías utilizadas en su producción (M). Para que esa mercancía sea convertida para forma dinero (D') es necesario comercializarla, sin embargo, como vimos, la demanda no siempre es efectiva, solvente. Un esquema que surgió, fruto de la ola de expansión de las políticas sociales en la segunda mitad del siglo XX, fue el préstamo al consumidor con intereses subsidiados (-) por el fondo público. Otro era la financiación por una institución 
privada con tasas de interés de mercado (++). Esas instituciones originadoras de créditos inmobiliarios pueden repasar esas deudas y las securitizadoras pueden utilizarlas para constituir títulos financieros.

El lado de la derecha del diagrama 2 representa este proceso. En él, el paso del tiempo entre la obtención de la mercancía y la aprobación de la gestión de su pago es incorporado por la duplicación de la representación visual del consumidor final, la cual presenta simultáneamente dos momentos temporalmente diferentes, la recepción de la mercancía y la aprobación de la deuda. Conviene tener en mente que el diagrama visualiza una explicación dialéctica, en la cual la incorporación del tiempo se da por el apunte de los elementos que constituyen una relación que reproduce en la mente el movimiento de lo real, y no por su laminado, como se hace en una animación, y tal como se incorpora a las metodologías positivistas. Así el consumidor final, que recibe la mercancía (M') del productor a cambio del valor (D'), asume una deuda con su agente

\section{Diagrama 2 - Circulación del capital monetario a partir de la producción inmobiliaria}

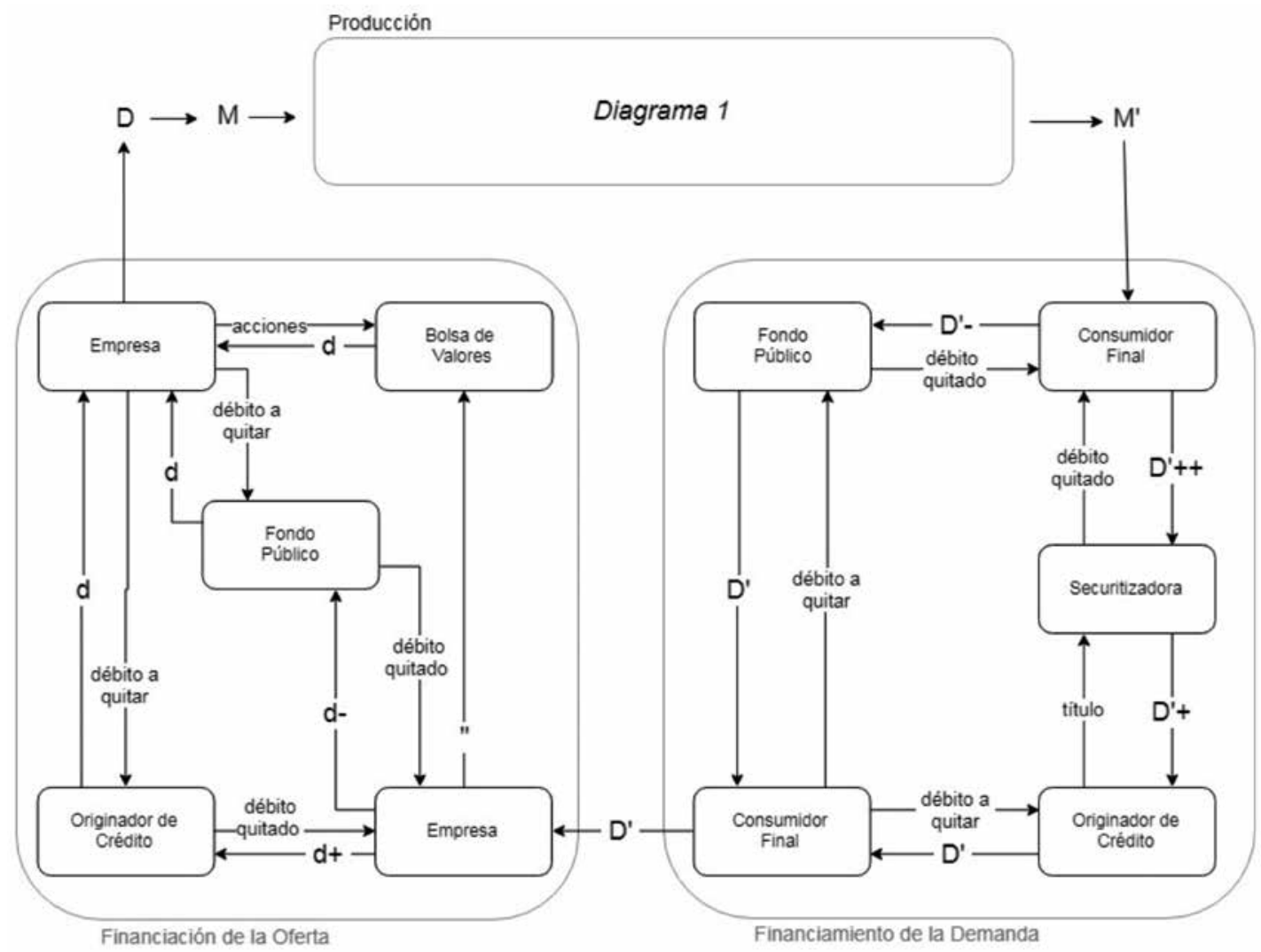

Diagrama elaborado por los autores 
financiador público (D'-) o privado ( $\left.\mathrm{D}^{\prime}++\right)$.

Como señalamos más arriba, el volumen del capital (D) movilizado para la compra de las mercancías necesarias al proceso productivo, por debajo de los beneficios extraordinarios, determina el volumen del excedente pasivo de ser convertido en plusvalía ('). Como también vimos, el empresario de la rama puede recaudar ese valor por diferentes medios, además de su ahorro. Puede conseguir algún valor (d) con prestamistas (originadores de crédito) a intereses de mercado $(+)$, emitiendo obligaciones, por ejemplo. Puede, por medio de alguna política pública económica o social, conseguir un adelanto de capital (d) a intereses más bajos que los de mercado (-). O, por fin, puede ampliar el capital social de su empresa emitiendo acciones que darán derecho a rendimientos ("). Conforme a las opciones que haga, tendrá que ceder alguna parte de su excedente bajo alguna de las formas especificadas $(\mathrm{d}+\mathrm{d}, \mathrm{d}-\mathrm{o}$ ").

\section{2 - DISPOSITIVOS FINANCIEROS VINCULADOS AL SEGMENTO INMOBILIARIO EN BRASIL}

En el desarrollo del debate reciente sobre el papel y el peso de las finanzas en la coordinación de la producción inmobiliaria en Brasil es posible observar el contorno de al menos tres momentos que se esbozan también en la historia de las prácticas de financiamiento de la oferta y la demanda. Sin embargo, los desarrollos y dispositivos que se han superpuesto $y$, a menudo, se han vuelto simultáneos nublan los límites entre tales momentos. El corte empírico y metodológico considera el período de referencia comenzando con la reestructuración del mercado tras el colapso del BNH, a mediados de la década de 1980.

Uno de los primeros movimientos del mercado brasileño que ha señalado con claridad la emergencia del segmento inmobiliario como un importante foco de absorción lucrativa de los excedentes producidos en los tradicionales medios de valorización del capital, fue la canalización de recursos que las Entidades Cerradas de Previsión Complementaria (EFPC), los llamados fondos de pensión (FP), se dirigieron a la producción de edificios corporativos. Durante la segunda mitad de los años 1980 y buena parte de los años 1990, ese flujo de inversiones representó la apertura de un nuevo y dinámico mercado para el segmento de incorporaciones. No sólo esa demanda ayudó a consolidar una nueva tipología de edificación y una dinámica geográfica renovada en la metrópoli, en perfecta sintonía con el nuevo momento para el cual se preparaba la economía brasileña, como reafirmó la centralidad de São Paulo en el marco nacional, produciendo, al mismo tiempo, una nueva centralidad de los negocios en el interior de la mayor metrópoli de América del Sur (CARLOS, 2001, MELO, 1990).

La crisis de las políticas desarrollistas (FIORI, 2003), el impacto de la reestructuración productiva (AGLIETA, 1997, HARVEY, 1994, LIPIETZ, 1984), los efectos de los diversos planes de estabilización monetaria con apertura de mercado y privatizaciones (BRUNO, 2008), el aumento del peso de los ingresos no operativos y de la riqueza financiera en la economía en general (BRUNO, 2007, PAULANI, 2009) y el proceso de centralización capitalista resultante de la reducción de la demanda (MIRANDA y TAVARES, 1999) se resolvieron en un proceso de concentracióngeográfica delaliquidezy degestión 
de los negocios (manufactureros, de servicios y financieros) (CARLOS, 2004; LENCIONI, 2011; SIMONI-SANTOS, 2013). Simultáneamente, esa tendencia de concentración estaba ligada no sólo a un desplazamiento espacial de las actividades, sino, sumándose a ella, a la emergencia de una dinámica directamente ligada a la producción del espacio.

Todo este proceso hizo emerger una rama renovada de empresas que tomó el doble papel de preparar un área específica de São Paulo para los nuevos dueños del capital concentrado y sus prestadores, construyendo los edificios de alto estándar que componen la imagen de la cara global de la metrópoli (Figura 1), y de alinear el capital monetario portador de intereses con los rendimientos resultantes de esta compleja dinámica espacial. También como resultado y condicionante del éxito de esa relación, una nueva centralidad fue producida en São Paulo: la centralidad de los negocios (Figura 2).

El modo de operación de las conexiones entre la producción inmobiliaria y el capital monetario concentrado se dio en ese momento con los fondos de pensiones constituyendo la mayor parte de la demanda y haciéndose propietarios, sobre todo, de los edificios corporativos de alto estándar, los llamados triple A o AAA. Los ingresos del negocio para los fondos provenían de los alquileres de esos espacios (edificios, lajas y unidades) para grandes empresas y oficinas que preferían no inmovilizar su capital en la compra de esos fragmentos del espacio construido (CARLOS, 2001).

Regulados en 1993, los Fondos de Inversión Inmobiliaria (FIIs) reúnen inversiones de las más diversas naturalezas, del ahorro individual a algunos capitales de otros inversores institucionales. Bajo el dominio de los FIIs, esas

\section{Figura 1 - Centralidad de los negocios en São Paulo}

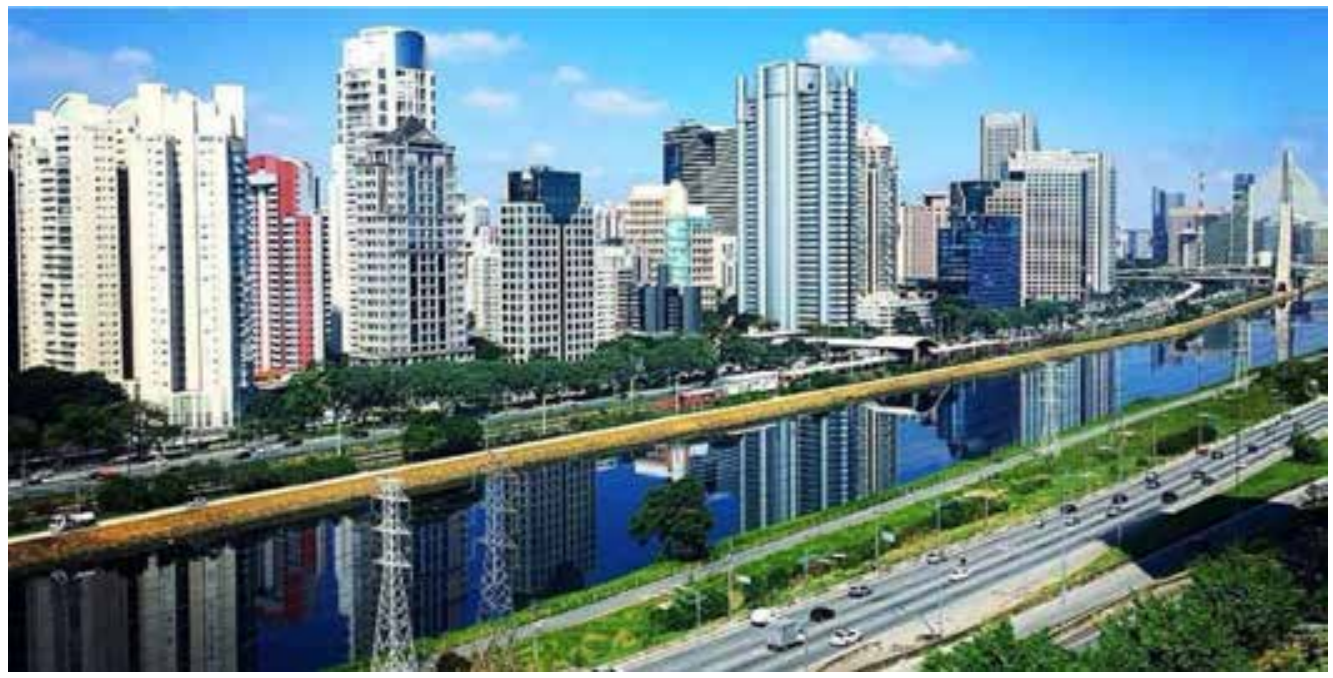

Visión de la nueva centralidad de los negocios en el Ilamado 'vector suroeste' de São Paulo. Foto: Tiago Pechin 


\section{FIGURA 2 - LANZAMIENTOS DE UNIDADES COMERCIALES EN SÃO PAULO POR DISTRITOS DE 1992 A 1999}

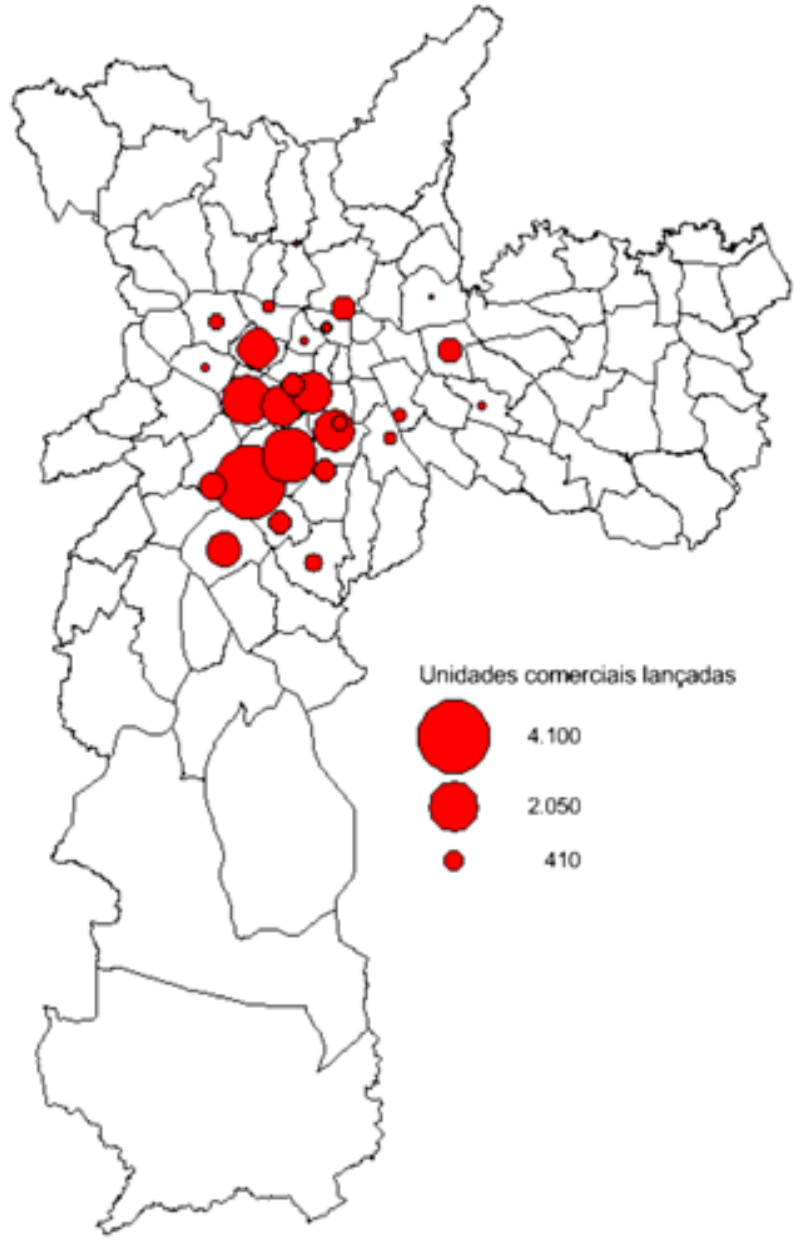

Concepción: César Simoni Santos. Elaboración: César Simoni Santos e Lívia Fioravanti. Fuente: Embraesp 2009

inversiones se transforman en capital a invertir en bienes inmuebles. Cada uno de estos inversores se convierte en un cotista y puede obtener ingresos provenientes tanto de los alquileres de los inmuebles y de la propia valoración patrimonial de los fondos. Además de constituir un nuevo dispositivo para la aplicación del ahorro dispersa, los FIIs acabaron sirviendo, en un primer momento, de medio de mantener los vínculos entre el excedente canalizado para los FPs y el mercado inmobiliario, cuando una legislación más restrictiva trató de barrer el ca- 
mino abierto entre ellos. Por el hecho de que la propiedad de cuotas de FIIs no se contabilizara como inversión en el mercado inmobiliario, sirvió de subterfugio a los fondos de pensiones que pasaron a tener severas limitaciones legales para inversiones en el mercado inmobiliario (FIX, 2011, p. 127; FIX, 2007, pp. 65-66). ${ }^{4}$

Sin embargo, de la misma forma que ese movimiento relacionado a la aplicación del patrimonio neto de los FPs puede ser señalado como un factor positivo en la historia del desarrollo de los FIIs en Brasil, esa proximidad puede estar ligada al florecimiento tardío de la modalidad, que, como se puede observar en el presente (gráfico 1), sólo ocurre al final de la primera década de este siglo.

En el marco de la primera década del siglo, el desarrollo y la expansión de la modalidad fueron débiles (SANFELICI, 2017, p. 376), incluso después de los cambios proporcionados por el advenimiento del Sistema de Financiamiento Inmobiliario (SFI) a partir de 1997. El papel y la proximidad que los FPs asumieron en relación con los FIIs pueden darnos algunas pistas acerca de ese escenario de contención. En primer lugar, porque la modalidad no se desarrolló inicialmente de hecho como un canal de inversión autónomo, una vez en que buena parte del funcionamiento de los FIIs enmascaraba una forma de actuación de los FPs. En segundo lugar, porque, como consecuencia del grado de dependencia de los FIIs en relación a las actividades de los FPs, hubo un duplicado de los nichos de inversión

Gráfico 1

Patrimonio Neto de los Fondos de Inversión Inmobiliario (2003-2016)

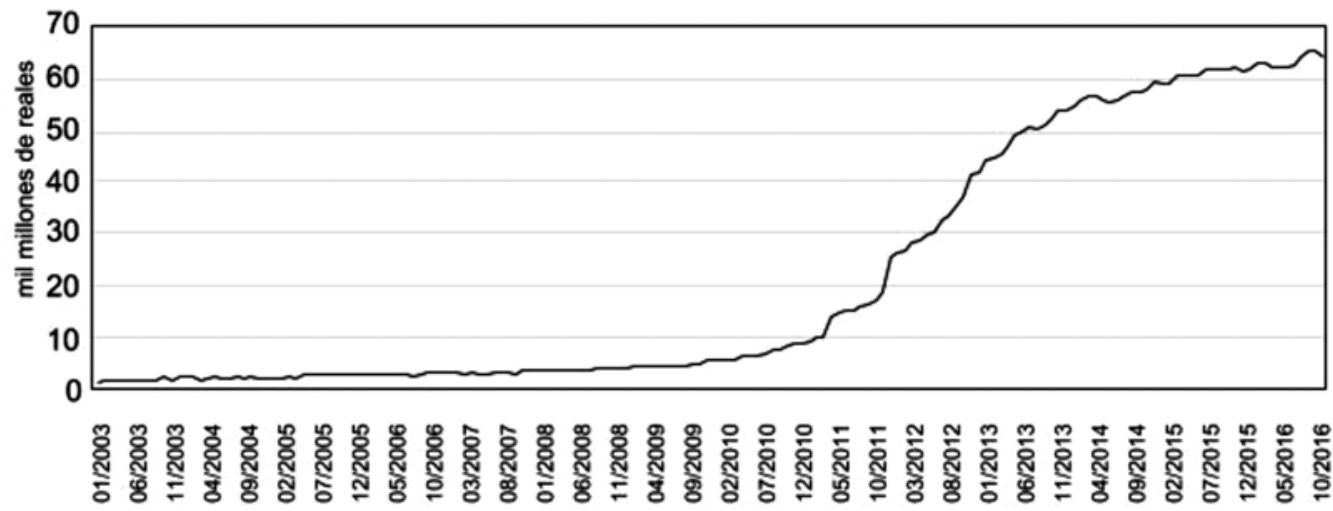

\section{Adequado de UQBAR 2017}

4 Los FPs "Ilegaron a tener el $22 \%$ de sus inversiones en inmuebles, en promedio, y algunos de ellos dirigieron más de la mitad de la cartera para activos inmobiliarios" (FIX, 2007: 69). que estaban acoplados a los portafolios preferenciales de los FPs. Los FIIs mantuvieron tres características fundamentales del patrón de inversión iniciado por los FPs durante los 
años 1980 y 1990:

- A pesar de la liberación para inversión en títulos relacionados al mercado inmobiliario, conferida por la Instrucción 472 de 2008 y emitida por la Comisión de Valores Inmobiliarios (CVM), 'aún predominan los FIIs que buscan renta a través del alquiler de los inmuebles,' totalizando estos 80,9\% del total de fondos activos (ALVAREZ, 2017, página 251);

- La concentración geográfica de los activos de los fondos es una característica marcada tanto en las escalas nacional y regional, como en la propia escala metropolitana, reforzando la tendencia a la producción de una nueva centralidad en la metrópoli de São Paulo en el llamado vector suroeste (ALVAREZ, 2017, p. 260; BOTELHO, 2007, p. 191; SANFELICI, 2017, pp. 382 y 388);

- El refuerzo a la tendencia a la concentración geográfica, a su vez, está directamente ligado al segmento de mercado al que los activos inmobiliarios de los FIIs están orientados. La clara opción por la propiedad en edificios corporativos, comerciales y de oficinas para un grupo de empresas sólidas y con capital abundante representó también la elección por una cierta área de la ciudad la mayoría de las veces (SANFELICI, 2017, p. 381).

La correlación entre la dinámica espacial y la proximidad de los Fondos con el sector de servicios del llamado "terciario avanzado" (SASSEN, 2006), que ya no era inédita (BOTELHO, 2007, CARLOS, 2001, FIX, 2007, MELLO, 1990), tiende a reaparecer también en el análisis del comportamiento geográfico y de los vínculos sectoriales de la emisión de los Certificados de Potencial Adicional Constructivo (CEPACs) (ALVAREZ, 2017, p. 260). Los CEPACs fueron diseñados para componer el cuadro de las Operaciones Urbanas Consorciadas (OUCs). A pesar de haber sido reguladas solamente en 2001, en el Estatuto de las Ciudades (Ley 10.257 / 2001), su primera aparición fue resultado de una acción del Ayuntamiento Municipal de São Paulo, en la primera mitad de los años 1990, con la intención de viabilizar el plan de la intervención que resultaría en la nueva centralidad financiera y de los negocios en la capital paulista, el vector suroeste, comprendiendo las Operaciones Urbanas Nova Faria Lima y Agua Espraiada (ALVAREZ, 2015; CARLOS, 2001; FIX, 2007). La venta del derecho constructivo alienado, que es el fundamento de los CEPACs, ya era prevista por el instituto de la Outorga Onerosa y fue incorporada a las OUCs. El dispositivo carga el derecho de construcción adicional por encima de lo permitido originalmente por la ley de zonificación en las áreas definidas por la propia OUC.

Por ser un título de mobiliario independiente de la propiedad del terreno, este derecho puede circular en el mercado financiero por caminos diferentes de aquel que normalmente representa la propiedad de la tierra. Este fue también uno de los primeros esfuerzos que resultó en el aumento de liquidez de la inversión respaldada en inmuebles. Además, el CEPAC diversificaba y ampliaba las formas de entrada del propio capital financiero en ese proceso, permitiendo la captación de recursos privados con el objetivo de la viabilidad de la intervención 
pública en el espacio urbano. Sin embargo, la desvinculación entre el potencial constructivo y el elemento suelo que el título supone no es completa. Vinculados ambos a la inversión inmobiliaria, la oscilación del precio del $\mathrm{m} 2$ puede interferir en el desarrollo del mercado de CEPACs. Así, como en los casos de los FII y de los FP, la demanda por CEPAC deberá orientarse hacia las áreas que presentan un potencial de atracción de inversiones inmobiliarias de alto nivel, no atendiendo a las áreas más carentes de intervención. Dada la dependencia del Estado en relación con esa fuente de medios de pago, la orientación de los recursos públicos deberá ser fuertemente sesgada.

Por lo tanto, una zona muy limitada de São Paulo se convirtió al mismo tiempo, (1) un globo de ensayo para las nuevas formas de inversión financiera que tuvo el mercado inmobiliario como la base de sus ganancias y (2) la solución de urgencias de un mercado en crisis, absorbiendo cantidades importantes del capital monetario concentrado. La producción del espacio, desde el inicio de esta etapa, ha sido el origen de la mayor parte de los beneficios del capital de las desarrolladoras y de una parte significativa de los rendimientos del capital portador de intereses.

Considerando los dispositivos y flujos movilizados en el momento en que se realiza el proceso de aproximación entre el mercado de capitales y la producción inmobiliaria, se observa aquí que, estando asociado a la realización del valor producido por la rama de edificaciones, los FPs y los FIIs pueden ser localizados en el Diagrama 1 en la posición del consumidor, beneficiándose con la mediación del acceso del consumidor final a la mercancía producida. Los CEPACs, que para su portador aparecen como un "simple título de renta", es computado por el productor como un activo del capital constante y, por sus características, posibilita la captura de rentas generadas por el aumento de la productividad resultante de los cambios en el coeficiente de aprovechamiento del terreno, ampliando los efectos de la verticalización sobre las ganancias del capital productor.

La introducción, en 1997, y el desarrollo del SFI marcan la segunda etapa del proceso de avance de las finanzas sobre el mercado inmobiliario brasileño. Si hasta ese momento el fin del BNH y la introducción de nuevos dispositivos financieros respaldados en inmuebles no habían formado un vínculo directo entre el mercado de capitales y la producción de viviendas, ese pudo haber sido el gesto decisivo. Uno de los primeros ensayos para la Financiación de la Política Habitacional fue así articulado 'de manera innovadora con la arquitectura financiera de los nuevos patrones de acumulación del capital' (ROYER, 2009: 13). La arquitectura del SFI busca reunir y potenciar algunos dispositivos financieros, priorizando 'la captación de recursos en un mercado secundario de títulos de créditos y recibibles inmobiliarios' (ROYER, 2009: 100). El modelo aparentemente se orienta por la premisa de la independencia en relación al compromiso de recursos y del funding directo, que eran la base del funcionamiento del antiguo SFH.

La creación de los instrumentos de securitización fue central. Entre los diferentes productos financieros relacionados con el crédito inmobiliario disponibles en el arreglo institucional brasileño y regulados por el SFI, los Certificados de Recibibles Inmobiliarios (CRIs) fueron aquellos considerados los más similares a los Residential Mortgage-Backed Securities 
(RMBS), la modalidad de activos securitizados con base en la deuda hipotecaria que fueron responsabilizados por el estallido de la crisis de 2008 en EEUU (ROYER, 2009). Los CRIs fueron introducidos originalmente en 1997, durante el gobierno de Fernando Henrique Cardoso por la Ley 9.514 que disciplina el SFI. Ellos son emitidos por empresas securitizadoras con base en préstamos inmobiliarios originados por ellas mismas. El sentido de estas formas de securitización inmobiliaria "es la conversión de activos de poca liquidez en títulos de gran liquidez, pasibles de ser absorbidos por el mercado financiero" (BOTELHO, 2007: 166).

Las Obligaciones, las Letras Hipotecarias y las Cédulas de Crédito Bancario, que ya existían, fueron adaptadas al nuevo ambiente de inversiones que se pretendía crear y sufrieron transformaciones en la integración al SFI. Los Fondos de Inversión Inmobiliario (FIIs), creados en 1993, también se incorporaron a la esfera del SFI y, a partir de 2002, comenzaron a negociarse en bolsa (BOTELHO, 2007: 166). Estas innovaciones en el financiamiento inmobiliario nacional dieron un nuevo impulso a un mercado de valores mobiliarios asentados en inmuebles y al mismo tiempo contribuyeron al avance del proceso de desintermediación bancaria del mercado inmobiliario mientras ofrecían posibilidades de ganancias financieras a los inversores.

Posteriormente, entre 2004 y 2005, ya durante el gobierno Lula (Leyes 10.931 y 11.196), fue creada la Cédula de Crédito Inmobiliario (CCI), emitida por originadores diversos de créditos inmobiliarios con base en los préstamos concedidos, y no sólo por securitizadoras. Entonces, también se permitió a las securitizadoras adquirir CCIs de otros agentes para la constitución de paquetes de deudas para emisión de CRIs. Así el arreglo institucional se habría completado. Sin embargo, en la aplicación de este modelo de financiación basado en la securitización, es fundamental que los papeles adquieran liquidez a partir del desarrollo de un mercado secundario relativamente dinámico y seguro. En el caso brasileño, la liquidez de los CRIs fue adquirida con base en la securitización de deudas originadas en el antiguo SFH, que aún sacudido por el cierre del BNH, mantiene sus actividades. Es decir, de hecho, el sistema que debería superar el SFH acabaría por viabilizarse por medio de él (ROYER, 2009).

Otro dispositivo importante creado en ese período fue la Letra de Crédito Inmobiliario (LCI), introducida por la Ley 10.931 de 2004. De hecho, actualmente es la principal forma de captación de recursos por las instituciones financieras para cesión de crédito inmobiliario, según analistas del mercado. Desde su creación, la emisión de ese título creció cada año. En 2016, por primera vez, se produjo una reducción, dada la falta de créditos concedidos para lastrar los títulos, recuperándose en 2017 (UQBAR 2017). Sin embargo, es claro el cambio de dirección de la curva de crecimiento del stock de esos títulos en la Central de Custodia y Liquidación Financiera de Títulos Privados (CETIP), donde se registran, y según se puede ver en el gráfico (Gráfico 2).

Este segundo momento, en lo que se refiere al impacto de las formas institucionales asumidas por la aproximación del mercado de capitales en relación a la producción inmobiliaria, se diferencia no sólo en la manera de intervenir en la demanda por edificios, sino por avanzar sobre la instancia de la financiación al 
Gráfico 2

\section{Valores de CRIs, CCls e LCI na Cetip (1997-2017)}

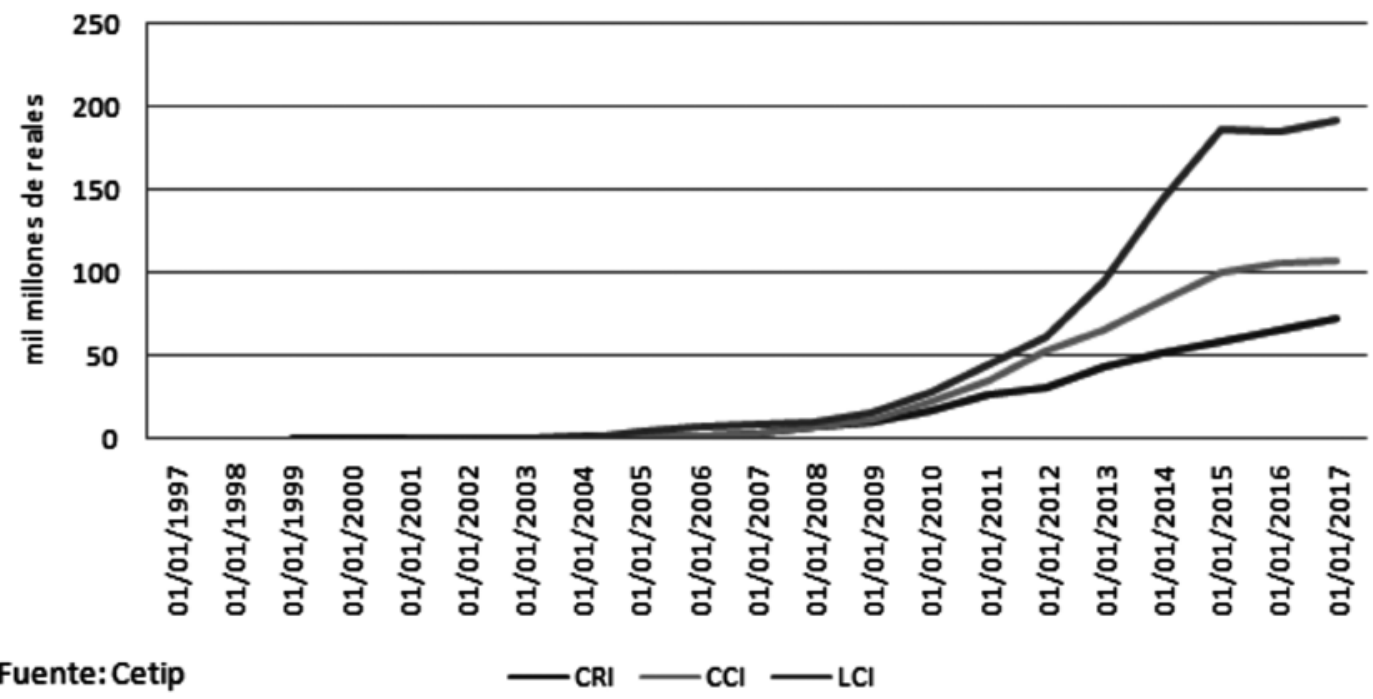

consumo, creando, incluso, un mercado secundario de deudas. El tercer momento se distingue de los demás por esa aproximación pasar a ser hecha también en el ámbito de la composición del capital social de las empresas y, por lo tanto, con un papel más importante en relación a la oferta que a la demanda, a pesar de los resultados globales de ventas tengan un impacto decisivo en la rentabilidad del capital monetario. El conjunto de los dispositivos presentados puede ser visualizado en el cuadro siguiente, que los caracteriza y los sistematiza a partir de los momentos propuestos.

Concomitantemente al proceso de desarrollo del SFI, en la segunda mitad de los años 2000, se observó una ola de apertura de capitales de las grandes promotoras del mercado brasileño. Esto intensificó los procesos de valorización financiera por la vía de la participación en el capital social de las empresas del segmento. De ese modo, el tercer momento puede ser caracterizado por la dinámica en el mercado accionista animada por los procesos de IPO o de Follow on de esas empresas. Para tener una idea, en el año 2006, Gafisa, Rossi, Cyrela y Company, algunas de las principales promotoras del mercado brasileño, ya habían hecho sus IPOs.

En un primerinstante, importaba paralas promotoras demostrar al mercado de capitales sus condiciones de sostener buenas y duraderas prestaciones. Considerando, sobre todo, el perfil de los inmuebles que componían las opciones de inversión de las grandes desarrolladoras en aquel momento, una característica marcada del segmento reaparece con fuerza: el problema de la oferta de terrenos (TOPALOV, 1979). A pesar de que el llamado déficit habitacional se mantuvo en niveles bastante elevados $y$, por lo 


\section{Cuadro sinóptico de los dispositivos presentados}

\begin{tabular}{|c|c|c|}
\hline momento & Dispositivos destacados & caracterización \\
\hline \multirow{3}{*}{$\begin{array}{l}\text { Entrada de los } \\
\quad \text { fondos }\end{array}$} & $\begin{array}{l}\text { Inversiones de las Entidades Cerradas de } \\
\text { Previsión complementaria }\end{array}$ & $\begin{array}{l}\text { Aumento de la demanda de edificios corporativos } \\
\text { derivado de la opción de inversión de los fondos de } \\
\text { pensión vinculados a grandes compañías estatales }\end{array}$ \\
\hline & Fondo de Inversión Inmobiliario (FII) & $\begin{array}{l}\text { Modalidad de inversión colectiva lastrado en activos } \\
\text { inmobiliarios }\end{array}$ \\
\hline & $\begin{array}{l}\text { Certificado de Potencial Adicional } \\
\text { Constructivo (CEPAC) }\end{array}$ & $\begin{array}{l}\text { Título mobiliario de cesión de derecho constructivo } \\
\text { adicional comercializado independientemente de la } \\
\text { propiedad del terreno. }\end{array}$ \\
\hline \multirow{3}{*}{$\begin{array}{l}\text { Introducción del } \\
\qquad \text { SFI }\end{array}$} & Certificado de Cobrables Inmobiliarios & $\begin{array}{l}\text { Título constituido por paquete de deudas de base } \\
\text { inmobiliaria securitizadas. }\end{array}$ \\
\hline & Cédula de Crédito Inmobiliario (CCI) & Título constituido por deuda de base inmobiliaria \\
\hline & Letra de Crédito Inmobiliario (LCI) & $\begin{array}{l}\text { Título constituido por deuda de base inmobiliaria } \\
\text { garantizado por un bien inmueble }\end{array}$ \\
\hline \multirow{3}{*}{$\begin{array}{l}\text { Apertura de } \\
\text { Capital }\end{array}$} & Inicial Public Offerings (IPO) & $\begin{array}{l}\text { Apertura de capital en bolsa de valores o emisión primaria } \\
\text { de acciones }\end{array}$ \\
\hline & Follow on & $\begin{array}{l}\text { Oferta posterior en la que una empresa que ya tenía capital } \\
\text { abierto vuelve a emitir acciones }\end{array}$ \\
\hline & $\begin{array}{l}\text { Programa Minha Casa Minha Vida } \\
\text { (PMCMV) }\end{array}$ & $\begin{array}{l}\text { Aumento de la demanda solvente por unidades } \\
\text { habitacionales nuevas promovido por la movilización del } \\
\text { fondo público }\end{array}$ \\
\hline
\end{tabular}

Cuadro elaborado por los autores

tanto, funcionó siempre como una promesa de desarrollo del segmento, la escasez de recursos dirigidos a los planes de provisión habitacional comprometió a las promotoras con la demanda de mercado. De salida fueron los edificios corporativos y de oficinas que drenaron las inversiones inmobiliarias. En los años 2000, los ejecutivos y empleados de la nueva centralidad de los negocios y de la gestión comenzaban a ser atendidos por una producción inmobiliaria que buscaba ofrecer productos de interés a una capa social con recursos propios para adquirir un inmueble. En el momento de los IPO, incluso con la evolución de los índices sociales y económicos ligados a las clases sociales más bajas, el foco de la producción y el mercado más dinámico de las grandes promotoras estaban todavía dirigidos hacia las áreas centrales de las grandes metrópolis. Todo ese arreglo creaba un problema de disponibilidad de terrenos.

Para conseguir atraer el capital bursátil en esas condiciones, la formación de un extenso banco de terrenos aparecía como sinónimo de la capacidad de lanzamiento futura y, por lo tanto, como factor de una estabilidad relativamente prolongada de la empresa. Esta estrategia dio lugar a una carrera para la formación y ampliación del stock de terrenos que sólo fue posible con el desplazamiento de esos land banks hacia las áreas más periféricas y de viabilidad económica cuestionable. Dado que la función de la acumulación de terrenos aumentaba su inviabilidad económica, tenía carácter puramente demostrativo y se definía en un escenario altamente competitivo, el movimiento resultó en un tipo de 'especulación 
financiera con terrenos', siendo responsable de la formación de una especie de capital ficticio formado por la acumulación de la propiedad de la tierra (SIMONI-SANTOS, 2013). Este fue uno de los indicativos de que la propiedad del suelo y la producción inmobiliaria pasaban a atender otros parámetros lógicos y de funcionamiento, subordinándose a las exigencias de la acumulación financiera (FIX, 2011).

Con la crisis de 2008, la fuga de capitales además de rebajar instantáneamente el precio de las acciones del segmento, dejó a las desarrolladoras descapitalizadas y atadas a un stock de suelo sin valor o liquidez. La solución que interesaba a las políticas monetaria y económica, buscando restituir la capacidad de atracción de inversiones que el segmento había desarrollado, pasó por el lanzamiento del Programa Minha Casa Minha Vida (PMCMV). El programa, que llegó a convertirse en el mayor programa habitacional del país, reunía las condiciones de solventar la demanda, dando realidad a los índices del déficit como indicadores efectivos de la actividad económica futura. La viabilidad de la demanda de estratos populares significó la realización del stock inerte de terrenos, lo que posibilitó, en ese primer momento, la reanudación de la posición de liquidez de las desarrolladoras (SIMONISANTOS, 2013).

Después del periodo de rescate, el programa se convierte en un fuerte elemento de conexión en la relación entre el mercado de capitales y el segmento de las desarrolladoras (SIMONI-SANTOS, 2018). Uno de los indicios es el desempeño de las acciones de las corporativas más fuertemente vinculadas al programa. MRV, una de las empresas que más producía en el marco del PMCMV, llegó a presentar una subida de casi el 300\% en el precio promedio diario de sus acciones entre 2015 y 2017 (infomoney, 2017). El perfil del programa, atado a las exigencias del mercado de capitales, resultó en ajustes en la estrategia de la empresa que tuvieron un profundo impacto en la geografía de la vivienda y en la tipología ofrecida. La propia MRV, por ejemplo, logró obtener grandes beneficios en la producción habitacional para bajos ingresos a través de la estandarización de las mercancías, de la adopción de tecnologías, que permitieron aumentar el control sobre el trabajo, y la utilización de instrumentos del mercado financiero, que financiaron la ampliación de su escala de producción tras la apertura de capital en la Bolsa de Valores (SHIMBO, 2010). La simbiosis entre el arreglo productivo y las ganancias financieras quedan evidentes en este caso.

\section{CONSIDERACIONES FINALES}

Cómo pudimos observar a lo largo de la exposición sobre los dispositivos abordados, tenemos, en el campo de estudios sobre la aproximación del mercado financiero en relación a la producción inmobiliaria en Brasil, un cuadro amplio y diversificado. Por un lado, los análisis enfatizan aspectos relacionados al impacto del cambio de la demanda por edificios, derivado de las estrategias propias de los FPs y de los FIIs, en la producción del espacio urbano. Por otro lado, esta bibliografía también llama la atención sobre los dispositivos que capturan valores en la instancia de la financiación del consumo y, en lo que se refiere a la vivienda, en el de la reproducción de la fuerza de trabajo. Estos estudios, en otro frente, aún, resaltan las formas de extracción y captación del excedente, 
situadas en el ámbito de la composición social de los capitales de las empresas actuantes en el ramo de edificaciones. A pesar del aumento en número e importancia de los dispositivos forjados aparentemente en y para el mercado de capitales que caracteriza el período abordado, las formas politizadas de promoción de la oferta inmobiliaria e incluso la participación del fondo público no dejaron de ser centrales. El propio proceso de expansión de las formas financieras de promoción de la oferta inmobiliaria ha contado explícitamente con la participación del Estado. Todo esto puede ser leído bajo el enfoque del dominio de las formas de injerencia de las finanzas sobre el proceso de producción del espacio urbano en la metrópolis contemporánea.

Este proceso no deja incólume la política de vivienda, sobre todo en su ámbito más social. El lanzamiento del PMCMV y su implementación modificó profundamente el sentido en que aparentaba desarrollarse, hasta entonces, la política social de provisión habitacional. Hasta mediados de los años 1990, la profundización de la asociación del Estado con la iniciativa privada en la producción de vivienda social se daba por la cesión de actividades, antes realizadas por el propio Estado, para las empresas del ramo. Esto permitió la ampliación de los rendimientos de esas empresas más allá de la extracción de la plusvalía en el proceso productivo, a través de la obtención de beneficios extraordinarios. Más recientemente, la producción de vivienda social y sus formas de financiamiento se movilizaron para garantizar la efectividad de las ganancias del capital financiero internacional. Así, el PMCMV, que aparenta ser el retorno al $\mathrm{BNH}$, es, de hecho, la forma de la captura de la política social de promoción habitacional por los intereses del capital financiero.

Los resultados de esta asociación tripartita entre el mercado de capitales, el fondo público y el capital de las promotoras han sido el origen de beneficios fabulosos. Los fines económicos suplantaron la finalidad social a partir de un amarre político difícil de desatar, lo que en los gobiernos más recientes ha dado señales de una profundización desastrosa con el descuido creciente con los más pobres pari-passu que el aumento de los recursos destinados a las capas de ingresos más alto. La universalidad de la forma monetaria pura, para la cual tiende el desarrollo de los dispositivos financieros de acumulación, no lleva consigo las otras dimensiones del proclamado y supuestamente bien intencionado proyecto moderno: ella no sólo es destituida de sus contenidos utópicos como, por su vocación narcisista, es contraria a las finalidades sociales de toda actividad por ella tocada.

\section{BIBLIOGRAFÍA}

Aglietta, M. 1997: Régulation et crises du capitalisme, Odile Jacob, Paris.
Alvarez, I. P. 2017: A produção de espaços financeirizados na metrópole de São Paulo. In: Ferreira, A.; Rua, J.; Mattos, 
R.C. (orgs) O espaço e a metropolização: cotidiano e ação. Rio de Janeiro:

Consequência: 241-266.

Alvarez, I. P. 2015: A produção e reprodução da cidade como negócio e segregação. In: Carlos; Volochko; Alvarez (orgs.). A cidade como negócio. São Paulo: Contexto.

Barbosa, I.S. 2010: “A realização de interesses da Iniciativa Privada na produção pública de Habitações Sociais do Estado de São Paulo no século XX." Revista de Economia Política e História Econômica, v. Ano 7, p. 77-122.

Barbosa, I. S. 2008: O Estado e a produção habitacional pública. Dissertação de Mestrado, Faculdade de Filosofia, Letras e Ciências Humanas, Universidade de São Paulo, São Paulo. doi:10.11606/D.8.2008. tde-05082009-155014. Recuperado em 2019-02-12, de www.teses.usp.br

Botelho, A. 2007: O Urbano em Fragmentos: a produção do espaço e da moradia pelas práticas do setor imobiliário. São Paulo: FAPESP/Anablume.

Bruno, M. 2007: "Financiarisation et accumulation du capital productif au Brésil les obstacles macro-économiques à une croissance soutenue ". Revue Tiers Monde, $n^{\circ} 189$, p. 65-92. 2007. DOI : 10.3917/rtm.189.0065.

Bruno, M. 2008 : "Régulation et Croissance Économique au Brésil après la libéralisation". Revue de la régulation [En ligne], 2e semestre/Autumn 2008. URL: http://regulation.revues.org/4103. (acesso em 20/03/2012).
Carlos, A.F.A. 2001: Espaço-Tempo na Metrópole: a fragmentação da vida cotidiana [Space-Time in the Metropolis: the fragmentation of everydaylife]. - São Paulo Carlos, A.F.A. 2004: São Paulo: do capital industrial ao capital financeiro [São Paulo: from industrial capital to financial capital]. - In: Carlos, A.F.A. and A.U. Oliveira (eds.): Geografias de São Paulo: a metrópole do século XX [Geographies of São Paulo: the metropolis of the 20th century]. - São Paulo: 1-84

Chesnais, F. 2010: “A proeminência da finança no seio do 'capital em geral', o capital fictício e o movimento contemporâneo de mundialização do capital" [The prominence of finance in the core of capital in general, the fictitious capital and the contemporary globalization movement of capital]. - In: Brunhoff, S., F. Chesnais, G. Duménil, D. Lévyand M. Husson (eds.): A Finança Capitalista [The Capitalist Finance]. São Paulo: 95-182

Fiori, J.L. 2003: O Vôo da Coruja: para reler o desenvolvimentismo brasileiro. Rio de Janeiro: Record.

Fix, M. 2011: Financeirização e Transformações Recentes no Circuito Imobiliário no Brasil. Tese de Doutorado apresentada ao Instituto de Economia da Unicamp. Campinas.

Fix, M. 2007: São Paulo Cidade Global: fundamentos financeiros de uma miragem [São Paulo Global City: financial foundations of a mirage]. - São Paulo

Harvey, D. 2006: Limits to Capital. New York. 
Harvey, D. 1994: A Condição Pós-moderna. Loyola. São Paulo.

Hilferding, R. 1985: O Capital Financeiro. São Paulo. Infomoney 2017: Daily quotation of shares of companies listed on Bovespa. - Online available at: www.infomoney. com.br/ mercados/empresas-bovespa, accessed 01/07/2017

Jaramillo, S. 2010: Hacia uma teoría de la renta delsuelo urbano [Towards a theory of urban ground rent]. - Bogotá

Lefèvre, R. 1982: Notas sobre o papel dos Preços de Terrenos em Negócios Imobiliários de Apartamentos e Escritórios na Cidade de São Paulo [Notes on the role of Land Prices in Real Estate Businesses of Apartments and Offices in the City of São Paulo]. - In: Maricato, E. (ed.): A Produção Capitalista da Casa (e da Cidade) [The Capitalist Production of the House (and the City)]. - São Paulo: 95-116

Lencioni, S. 2011: “A metamorfose de São Paulo: o anúncio de um novo mundo de aglomerações difusas". Revista Paranaense de Desenvolvimento. Curitiba, n. 120, jan/ jun. p.133-148. www.ipardes.pr.gov.br/ojs/ index.php/revistaparanaense. (acesso em 03/04/2012)

Lipietz, A. 1974: Le Tribut Foncier Urbain [The urban land charge]. - Paris

Lipietz, A. 1984: De la nouvelle division internationale du travail. Espaces et societés, Janvier-Juin, n. 44: 51-78.
Logan, J. e Molotch, H. 1987: "Urban Fortunes: the political economy of place", University of California Press.

Lojkine, J. 1971: Y à-t-il une rente foncière urbaine?[Is there an urban ground rent?].

- Espace et Societé 2: 89-94

Marx, K. 1988: Capítulo XXIV do Livro Terceiro de O Capital: O processo global da produção capitalista. São Paulo: Nova Cultural: 3-11.

Marx, K. 2011: Grundrisse: manuscritos econômicos de 1857-1858. São Paulo: Boitempo.

Melo, M.A.B.C. 1990: Estruturação Intra-urbana, Regimes de Acumulação e Sistemas Financeiros da Habitação: Brasil em perspectiva comparada [Intra-urban Structuring, Accumulation Regimes and Housing Financial Systems: Brazil in Comparative Perspective]. - Espaço e Debates: revista de estudos regionais e urbanos 31. - São Paulo: 37-51 Miranda, J.C. and M.C. Tavares 1999: Brasil: estratégias de conglomeração [Brazil: conglomeration strategies]. In: Fiori, J.L. (ed.): Estados e Moedas no Desenvolvimento das Nações [StatesandCurrencies in the Development of Nations]. - Rio de Janeiro: 327-350

Paulani, L. 2009: A crise do regime de acumulação com dominância da valorização financeira e a situação do Brasil. Estudos Avançados, 23(66), 25-39. Recuperado de http://www. revistas.usp.br/eav/article/view/10407

Royer, L. 2009: Financeirização da Política Habitacional: limites e perspectivas. Tese apresentada ao programa de Pós- 
Graduação em Arquitetura e Urbanismo da Universidade de São Paulo. São Paulo.

Sanfelici, D. 2017: La indústria financiera y los fondos inmobiliarios en Brasil: lógicas de inversión y dinâmicas territoriales. Economía Sociedad y Territorio, [S.1.], p. 367-397, mayo. ISSN 2448-6183. Disponible en: <https://est.cmq.edu.mx/ index.php/est/article/view/685/1276>. Fecha de acceso: 08 feb. 2019 doi:http:// dx.doi.org/10.22136/est002017685.

Sassen, S. 2006: Cities in a world economy. Third edition. - Thousand Oaks, CA

Shimbo, L. 2010: Habitação social, habitação de mercado: a confluência entre Estado, empresas construtoras e capital financeiro. Tese de Doutorado, Escola de Engenharia de São Carlos, Universidade de São Paulo, São Carlos. doi:10.11606/T.18.2010.tde-04082010100137. Recuperado em 2019-02-10, de www.teses.usp.br

Simoni-Santos, C. 2018: The geophagic nature of financial dominance in the Brazilian real estate market. - DIE ERDE 149 (4): 241-260. Disponiblen en: https://www. die-erde.org/index.php/die-erde/article/ view/413/pdf. Fecha de acceso: 10 enero 2019. DOI:10.12854/erde-2018-413.

Simoni-Santos, C. 2013: A nova centralidade da metrópole: da urbanização expandida à acumulação especificamente urbana [The new centrality of the metropolis: from expanded urbanization to specifically urban accumulation]. - Tese de Doutorado [PhD Thesis], Faculdade de Filosofia,
Letras e Ciências Humanas, Universidade de São Paulo. - São Paulo.

Simoni-Santos, C. andSanfelici, D. 2015: Caminhos da produção financeirizada do espaço urbano: a versão brasileira como contraponto a um modelo [Directions of the financialized production of urban space: the Brazilian case as a counterpoint to a standard]. - Cidades 12 (20): 4-34

Singer, P. 1982: O Uso do Solo Urbano na Economia Capitalista [The Use of Urban Ground in the Capitalist Economy]. - In: Maricato, E. (ed.): A Produção Capitalista da Casa (e da Cidade) [The Capitalist Production of the House (and the City)]. São Paulo: 21-36

Slater, T. 2015: Planetary rent gaps. - Antipode 49 (1): 1-24, doi:10.1111/anti.121852015

Smith, N. 1996: New Urban Frontier: Gentrification and the Revanchist City. - London

Soederberg, S. 2014: Subprime Housing Goes South: Constructing Securitized Mortgages for the Poor in Mexico. - Antipode 47 (2): 1-19, doi:10.1111/anti.12110

Topalov, C. 1987: Le logement en France: histoire d'une marchandise impossible. Paris : Presses de la Fondation Nationale des Sciences Politiques. ISBN : 2-7246-0545-4

Topalov, C. 1979: "Análise do Ciclo de Reprodução do Capital Investido na Produção da Indústria da Construção Civil”. In: FORTI (org). Marxismo e Urbanismo Capitalista. São Paulo: Livraria Editora Ciências Humanas: 53-80. 


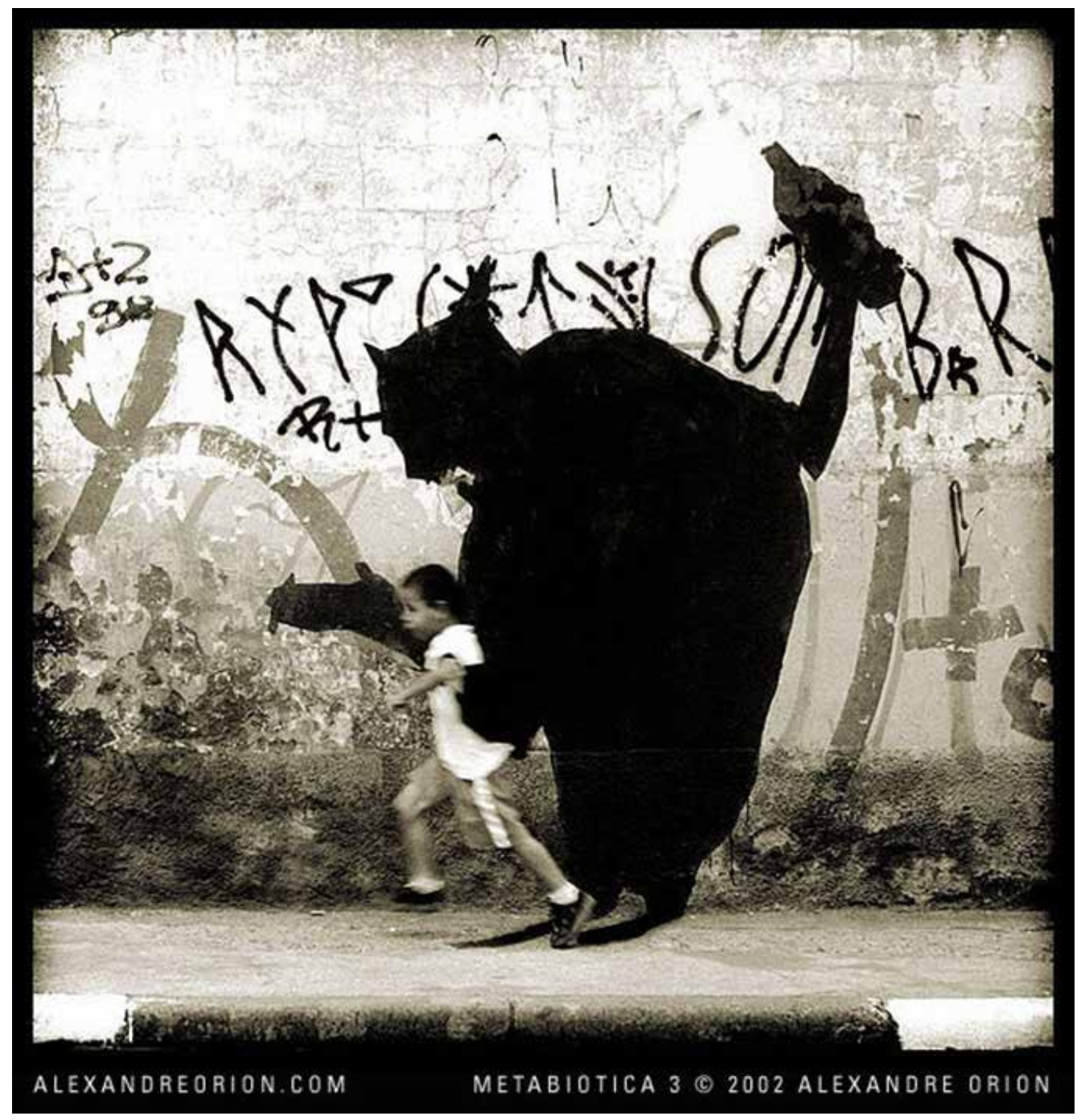

Metabiótica 3. 2002. Intervenção urbana seguida de registro fotográfico 